\title{
Differentiation of courtship songs in parapatric sibling species of dwarf stonebashers from southern Africa (Mormyridae, Teleostei)
}

\author{
Michael Lamml \& Bernd Kramer ${ }^{1)}$ \\ (Zoologisches Institut der Universität Regensburg, Universitätsstraße 31, \\ D-93040 Regensburg, Germany)
}

(Accepted: 24 April 2006)

\begin{abstract}
Summary
We describe the nocturnal courtship songs of male dwarf stonebashers, Pollimyrus castelnaui, from the Okavango River and its inland delta. We examined the question of whether the songs are sufficiently differentiated from those of its parapatric sibling species, the only recently discovered P. marianne from the Upper Zambezi River, to form a potential cue for mate choice. Both species vocalised two sound types in courtship, the moan and the grunt, which they combined into long songs in similar fashion. However, one sound type was clearly differentiated: while $P$. castelnaui moans were of a husky quality and composed of three or four broadband formants, $P$. marianne moans were more tonal, with a single spectral line dominating the first and any higher formants (and a smaller bandwidth $\mathrm{BW}_{-10 \mathrm{~dB}}$ for the dominant frequency of the first formant). Moan and Grunt Duration and the moan Pulse Group Period (mPGP) were longer, and the latter more variable, in $P$. castelnaui compared to $P$. marianne (range of mPGP: $10-30 \mathrm{~ms}$ in P. castelnaui, $7-16.7 \mathrm{~ms}$ in P. marianne). $P$. castelnaui grunts were of longer duration and composed of more pulses than those of P. marianne. A single male from the contact zone between the Okavango and the Zambezi, the lower Kwando River, resembled P. castelnaui in moan $\mathrm{BW}_{-10 \mathrm{~dB}}$ but $P$. marianne in Moan Duration and mPGP. Both southern African species thus vocalise in a species-specific fashion. Since in both species several characteristics of both moans and grunts show high between- and low within-male variability, mate choice may be selective for individual highquality males characterised by acoustic features.
\end{abstract}

\footnotetext{
1) Corresponding author's e-mail address: bernd.kramer@biologie.uni-regensburg.de 
Keywords: acoustic communication, electric fish, reproduction, species recognition, variability, vocalisation.

Abbreviations: BD, Body Depth; CV, coefficient of variation; EOD, Electric Organ Discharge; gD, Grunt Duration; gIPI, Grunt Inter-Pulse Interval; gPAF, Grunt Peak-Amplitude Frequency; gPD, Grunt Pulse Duration; gPRR, Grunt Pulse Repetition Rate; IGI, Inter-Grunt Interval; jnd, just noticeable difference; $|\mathrm{M}|$, absolute value of the mean; $\mathrm{mD}$, Moan Duration; $\mathrm{mBW}_{-10 \mathrm{~dB}}$, bandwidth of moan at $-10 \mathrm{~dB}$ of Peak-Amplitude Frequency; mgD, Duration of Moan-Grunt bout; mPAF1, Peak-Amplitude Frequency of the first formant of a moan; mPGP, Moan Pulse-Group Period; SD, standard deviation; SE, standard error; SL, Standard Length; SPL, Sound Pressure Level.

\section{Introduction}

The dwarf stonebasher Pollimyrus castelnaui (Boulenger, 1911) inhabits the Okavango River and Delta, whereas its recently discovered sister species, Pollimyrus marianne, inhabits the Upper Zambezi River (Kramer et al., 2003). Both mega systems are sporadically linked by a tenuous water connection via the intermediate Kwando/Linyanti System, a tributary of the Zambezi River (for details, see Kramer et al., 2003). Although they cannot be distinguished by the naked eye, both species are well differentiated in morphology, genetics, and the waveform of their electric organ discharges (EODs; Kramer et al., 2003; Markowski et al., subm.), and are regarded as vicariant sibling species.

In addition to their electrical signalling by EODs, the males of Pollimyrus marianne vocalise mating calls during courtship and spawning (Lamml \& Kramer, 2005), as also known for two Pollimyrus species from West Africa (review, Crawford, 1997). While the song elements are basically similar among all Pollimyrus species studied so far, their complexity and sequence in a song may differ. Pollimyrus marianne males produce single tonal moans, or, when a female approaches the nest site, a long-lasting moan that is superimposed by several pulsatile grunts (Lamml \& Kramer, 2005). Pollimyrus adspersus from the West African Niger River generates long courtship songs in which moans alternate with pulsatile grunts, which are often terminated by a long growl, whereas its sibling species Pollimyrus isidori vocalises a single grunt followed by several short tonal moans (Crawford et al., 1986; Bratton \& Kramer, 1989; Crawford et al., 1997a, 1997b).

We here describe the mating songs of $P$. castelnaui for the first time. In contrast to the two West African Pollimyrus species, EOD waveform is well 
differentiated between the two southern African species, thus qualifying for a cue in Paterson's Specific Mate Recognition System (Paterson, 1985). It was unknown whether the mating songs of the two southern African species were sufficiently differentiated to fulfill a similar function. Therefore, we critically compared $P$. castelnaui's mating song characteristics with those of $P$. marianne. Additionally, we studied whether inter-individual variability in sound characteristics would potentially support selective mate choice or individual recognition, in view of the acoustic discrimination capabilities found in West African Pollimyrus species (Marvit \& Crawford, 2000a, 2000b; Fletcher \& Crawford, 2001).

\section{Methods}

\section{Animal collection and care}

The P. castelnaui (Boulenger, 1911) were caught in March 2002 in the Okavango delta near Makwena, Sepopa Nguma lagoon, near the panhandle (19 $03^{\prime} 45.3^{\prime \prime}$ S, $22^{\circ} 23^{\prime} 24.3^{\prime \prime}$ E; coll.: F.H. van der Bank; Figure 1A). One male had been caught already in August $2000\left(18^{\circ} 57^{\prime} 30.6^{\prime \prime} \mathrm{S}, 22^{\circ} 23^{\prime} 12.0^{\prime \prime} \mathrm{E}\right.$; coll.: R. Bills). Three P. marianne Kramer et al., 2003 males were caught on 22 August 1999 in a side-channel of the Upper Zambezi River near Kalim-

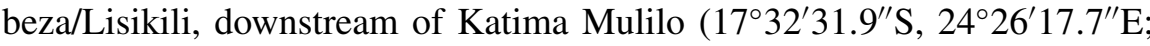
coll.: F.H. van der Bank \& B. Kramer; Figure 1B). One P. marianne male (no. 04) was reared in captivity (2002). An additional $P$. marianne male originated from the Kwando River (caught in August 2004 at Kongola bridge; $17^{\circ} 47^{\prime} 26.7^{\prime \prime} \mathrm{S}, 23^{\circ} 20^{\prime} 40.0^{\prime \prime} \mathrm{E}$; coll.: F.H. van der Bank \& B. Kramer). The species identity of all animals was confirmed by their characteristic EOD waveform. The males' sex was apparent from an indentation of the anal fin base (see Kramer et al., 2003).

Either male-female pairs, or one to three males (in the largest aquaria) were kept together with several females in aquaria of different size (150780 litres). These were well equipped with stones and roots as shelters and planted with Vesicularia dubyana and Cryptocoryne affinis. The aquarium bottom was covered with sand. The L:D cycle was 12:12 hours. Animals were fed on chironomid larvae five to six times per week. 


\section{Behavioural observations}

We observed a reproductive male's (focal animal) nocturnal behaviour from the early stages of a male's reproductive cycle on, when a male started to build a nest in its territory. The fish showed reproductive behaviour under environmental conditions that were allowed to vary between 50-200 $\mu \mathrm{S}$ $\mathrm{cm}^{-1}$ water conductivity and $23-26^{\circ} \mathrm{C}$ temperature. We conducted nocturnal video recordings using infrared illumination and an infrared-sensitive camera (model Panasonic FK 6990-IQ; videotape recorder, Panasonic AG-7330, Hifi, S-VHS). We placed a hydrophone in a male's territory close to its nest and recorded all acoustic signals continuously from 10 P. castelnaui males (SL, $5.9 \pm \mathrm{SD} 0.29 \mathrm{~cm}$ ), four P. marianne males (SL, $6.0 \pm \mathrm{SD} 0.38 \mathrm{~cm}$ ), and one male from the Kwando River (SL, $5.2 \mathrm{~cm}$; only moans). Ten males that vocalised courtship songs (Moans and Moan-Grunt bouts) also reproduced successfully, and reared larvae in their nests. Five males, among them the single Kwando male, did not reproduce. Two of the non-reproducing males had vocalised only moans, the remaining three had vocalised Moan-Grunt bouts in addition to pure moans.

\section{Analysis of acoustic signals}

All sounds were monitored with a hydrophone (Brüel \& Kjær, Model 8101, $1 \mathrm{~Hz}-125 \mathrm{kHz}$ frequency response), amplified with a measuring amplifier (Brüel \& Kjær 2610, $2 \mathrm{~Hz}-200 \mathrm{kHz}$ frequency response) and tape-recorded on the first audio-track of the video-recorder. To reduce low-frequency noise, the amplified hydrophone output was bandpass-filtered ( $40 \mathrm{~Hz}-10 \mathrm{kHz}$ passband, $24 \mathrm{~dB}$ attenuation / octave, linear phase response) using an electronic filter (Wavetek Rockland Inc., Model 452). Vocalisations were digitised from videotape recordings at $48 \mathrm{kHz}$ sampling rate and 16 bit vertical resolution using the standard soundcard of an IBM-compatible computer (Pentium IV, 1.7 GHz), controlled by the software Avisoft-SASLabPro Version 4.33 (Avisoft Bioacoustics, Berlin, Germany). For analysis we only used sounds we were able to assign to a specific individual, based on relative sound pressure level and fish distance from the hydrophone. Sounds with good signal-tonoise ratio were typically generated within $20 \mathrm{~cm}$ of the hydrophone.

Table 1 summarises all sound characteristics and specifies the measuring methodology. Temporal parameters, such as Moan-Grunt bout Duration 


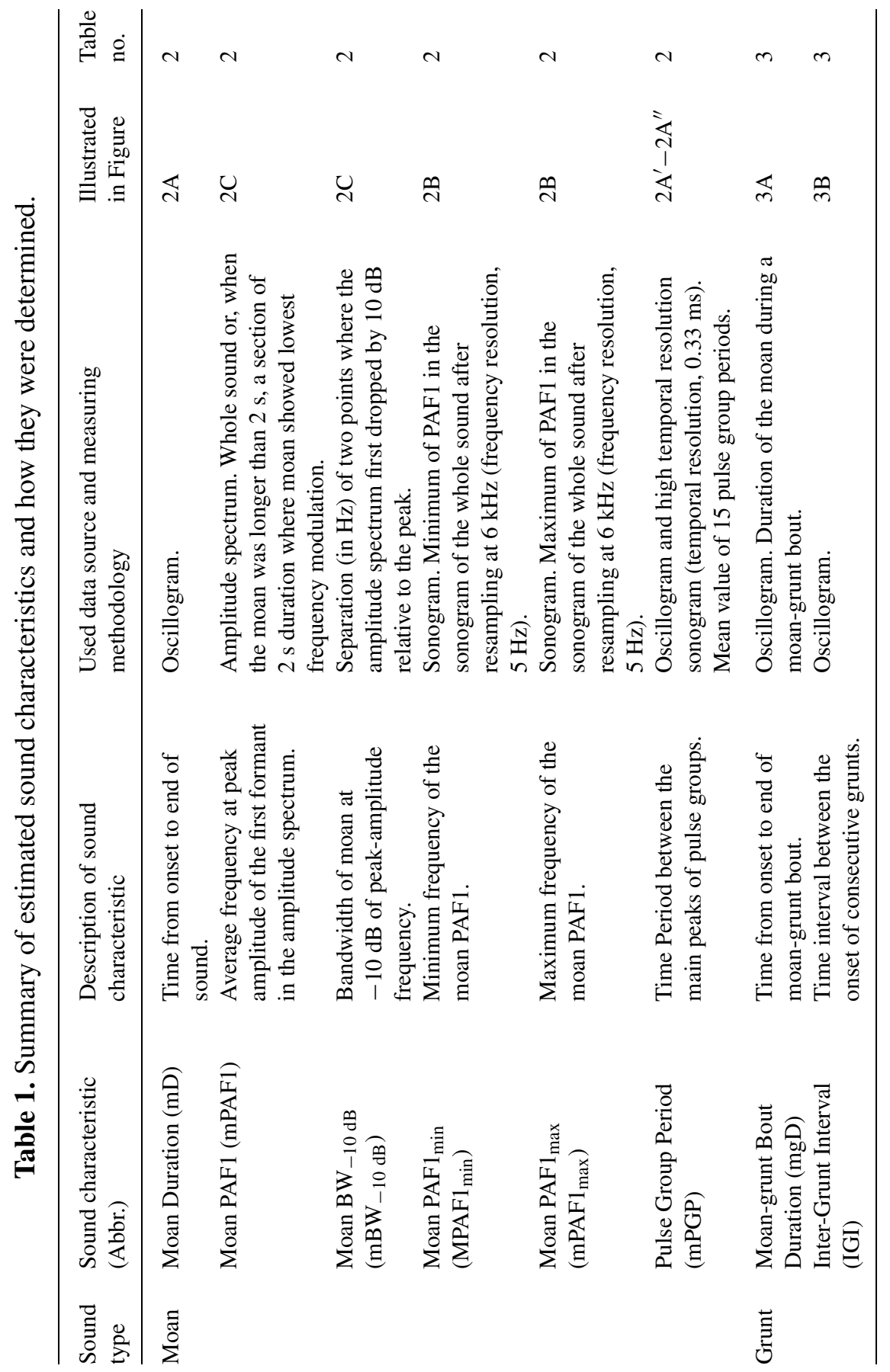




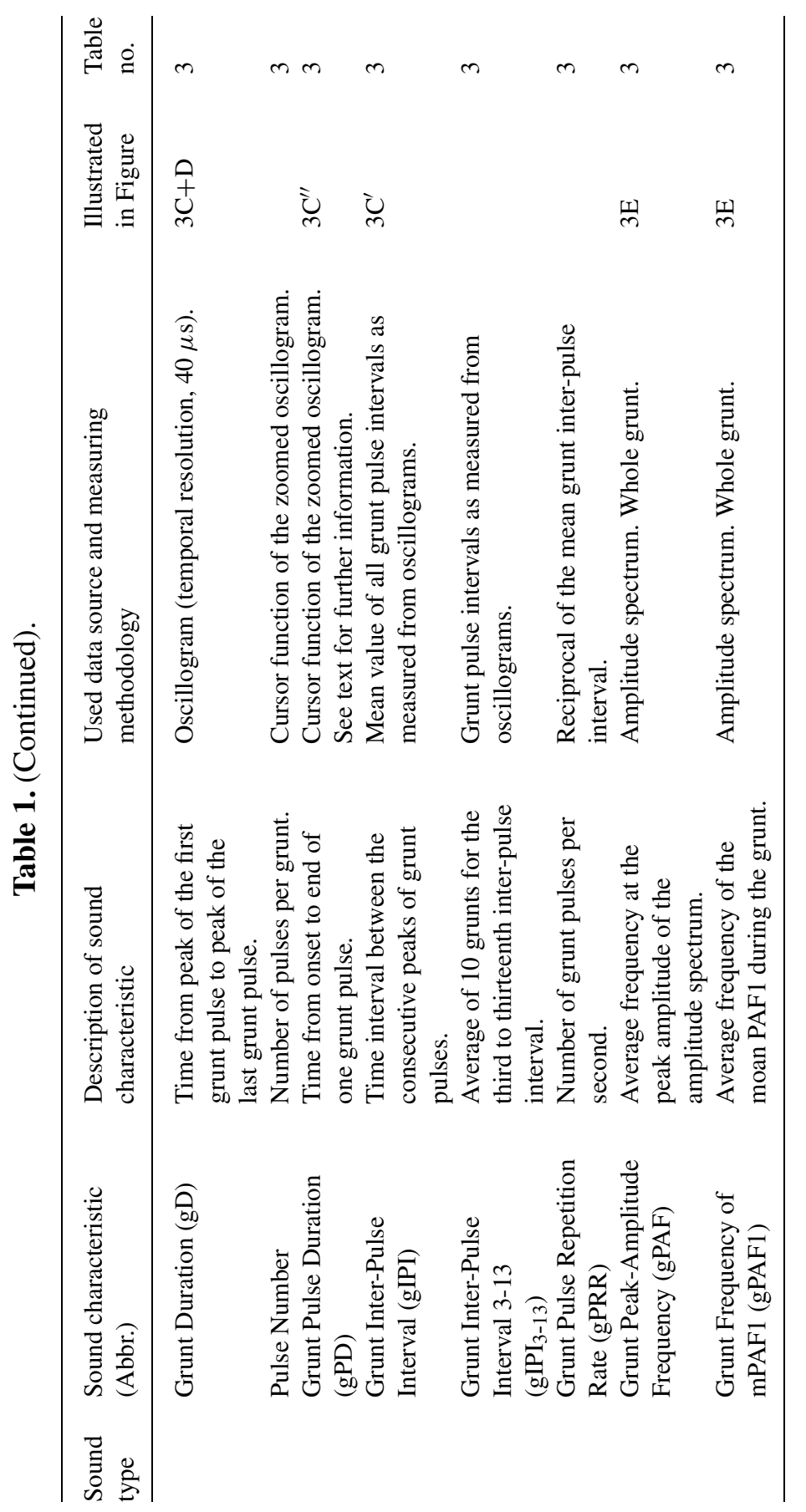


$(\mathrm{mgD})$ and Moan Duration $(\mathrm{mD})$, were measured from sound pressure oscillograms, with grunt Pulse Duration (gPD) and grunt Inter-Pulse Intervals (gIPI) estimated visually from zoomed oscillograms with Avisoft's cursor function. Grunt Pulse Duration was defined as the time period during which the pulse sound wave clearly emerged from the superimposed moan oscillations. Grunt Inter-Pulse Intervals were measured by visually estimating each time interval between adjacent peaks of grunt pulses. Moan Pulse-Group Period (mPGP) describes the time period between the maxima of adjacent pulse groups of a moan. Zoomed oscillograms and a concurrent sonogram representation of high temporal resolution $(0.33 \mathrm{~ms})$ were used to determine the pulse of highest intensity within a single pulse group. We averaged 15 mPGPs from the middle section of a moan, where it showed the lowest frequency modulation. Mean gPD was calculated by averaging the duration of 15 consecutive grunt pulses. The mean gIPI was defined as the average of all grunt IPIs.

After resampling the digitized vocalisations at $6 \mathrm{kHz}$, using an antialiasing filter (Avisoft), we determined the Peak-Amplitude Frequency (PAF) and the moan bandwidth at $-10 \mathrm{~dB}$ relative to the peak amplitude $\left(\mathrm{mBW}_{-10 \mathrm{~dB}}\right)$ by FFT amplitude spectra which were usually generated based on 2048 to 16384 time data points. Therefore, FFT amplitude spectra comprised between 1024 to 8192 frequency data points (resolution: 0.366-2.93 $\mathrm{Hz}$ ). To determine the absolute SPL of vocalisations generated at about 10 $\mathrm{cm}$ from the hydrophone we read the relative SPL off the measuring amplifier, and calculated the absolute values ( $\mathrm{dB}$ re: $1 \mu \mathrm{Pa}$ ) based on the sensitivity of the hydrophone.

In order to know whether the temporal fine structure (IPI) of a sound was affected by the distance of the sound source from the hydrophone we made test measurements with single-cycle sine-wave pulses of $1 \mathrm{~ms}$ duration, repeated at an IPI of 5, 10, 15, 20 and $25 \mathrm{~ms}$, that were generated by a function generator (Hewlett-Packard model 3314A). The output of this device was connected to an underwater loudspeaker (model UW-30 Diatran, University Sound, Oklahoma City) via a power amplifier (model AD5250B; Sherwood Europe $\mathrm{GmbH}$ ). Using one of the recording aquaria in which several males of both species had produced their vocalisations (dimensions, $240 \times 65 \times 50 \mathrm{~cm}$ high), we recorded the test signals at $1-55 \mathrm{~cm}$ distance from the loudspeaker, and did not measure any distance-dependent effect on the temporal structure 
(IPI) of the recorded sounds. In the near field, signal intensity fell off dramatically with distance: $-15 \mathrm{~dB}$ re: $1 \mu \mathrm{Pa}$ between 1 and $10 \mathrm{~cm}$ distance, and $-13.5 \mathrm{~dB}$ re: $1 \mu \mathrm{Pa}$ between 10 and $30 \mathrm{~cm}$, but only $-1.5 \mathrm{~dB}$ re: $1 \mu \mathrm{Pa}$ between 30 and $55 \mathrm{~cm}$ distance. The absolute SPL of the signal was $115 \mathrm{~dB}$ re: $1 \mu \mathrm{Pa}$ at $1 \mathrm{~cm}, 100 \mathrm{~dB}$ re: $1 \mu \mathrm{Pa}$ at $10 \mathrm{~cm}, 86.5 \mathrm{~dB}$ re: $1 \mu \mathrm{Pa}$ at $30 \mathrm{~cm}$ and $85 \mathrm{~dB}$ re: $1 \mu \mathrm{Pa}$ at $55 \mathrm{~cm}$ distance from the loudspeaker.

\section{Statistical analysis of vocalisations}

Statistical analyses were performed with the software packages StatView version 5.0 (SAS Institute Inc.) and Prism version 3.0 (GraphPad Inc.). Because sound characteristics may depend on the size of a resonant structure rather than on SL, we roughly calculated an individual's body size as the product of Standard Length (SL) times Body Depth (BD). SL is defined as the distance between tip of snout and midbase of caudal fin. BD is the greatest vertical distance across the body (see Figure 3 in Kramer et al., 2003). We measured SL and BD from photographs taken within a few weeks before or after the sound recordings.

The vocalisations of $P$. castelnaui and $P$. marianne were recorded at a mean water temperature of $25^{\circ} \mathrm{C}$, whereas those of $P$. adspersus and $P$. isidori (Crawford et al., 1997b) were recorded at about $28^{\circ} \mathrm{C}$. To compare the vocalisations of West and southern African stonebashers, temperature compensation to $28^{\circ} \mathrm{C}$ was applied, using $\mathrm{Q}_{10}$ values of 1.06 for $\mathrm{mD}, 1.8$ for $\mathrm{mPAFl}$, 1.99 for $\mathrm{gD}$ and 2.02 for $\mathrm{gPRR}$, as determined from a male $P$. marianne (Lamml \& Kramer, 2005).

Coefficients of variation $(\mathrm{CV})$ were calculated as $\mathrm{CV}=\mathrm{SD} /|\mathrm{M}| \times 100$.

\section{Results}

The courtship songs of $P$. castelnaui compared with those of $P$. marianne

The males of both sibling species, $P$. castelnaui and $P$. marianne, vocalised basically the same two categorically different sound types, moans, composed of pulse groups that were repeated hundreds of time (Figures 1,2), and grunts that consisted of short sequences of strong acoustic pulses (Figure 3). The sequence of sound patterns in a courtship song was similar between the two species. Moans and grunts were generated ever more frequently when a female started visiting a male's territory during the prespawning nights. 
A
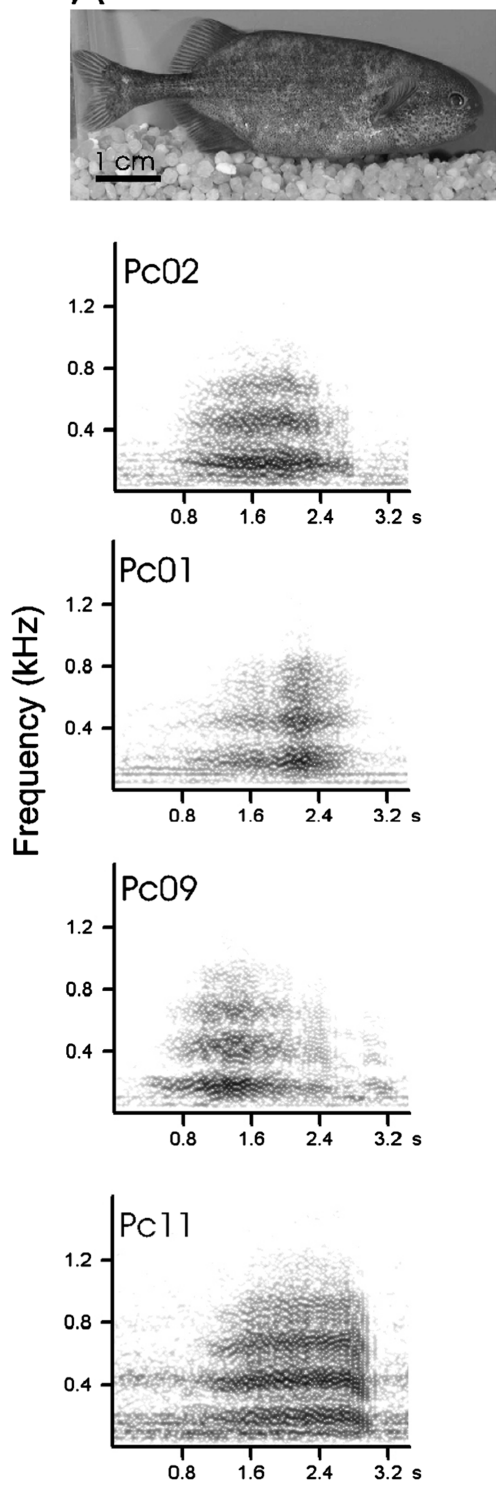

Time (s)
B
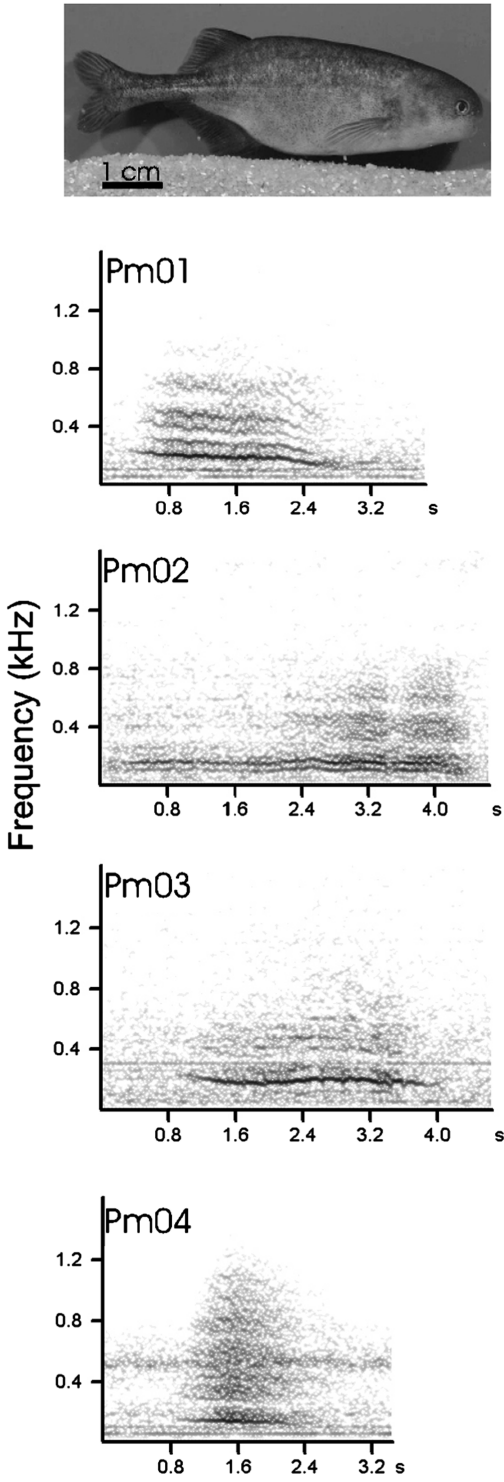

Time (s)

Figure 1. (A) A Pollimyrus castelnaui male from the Okavango; (B) a Pollimyrus marianne male from the Upper Zambezi River. Note indented anal fin base. Below, moans recorded from four $P$. castelnaui (left) and four P. marianne individuals (right), shown as sonograms (frequency resolution, $5 \mathrm{~Hz}$; temporal resolution, $10.7 \mathrm{~ms}$ ). 


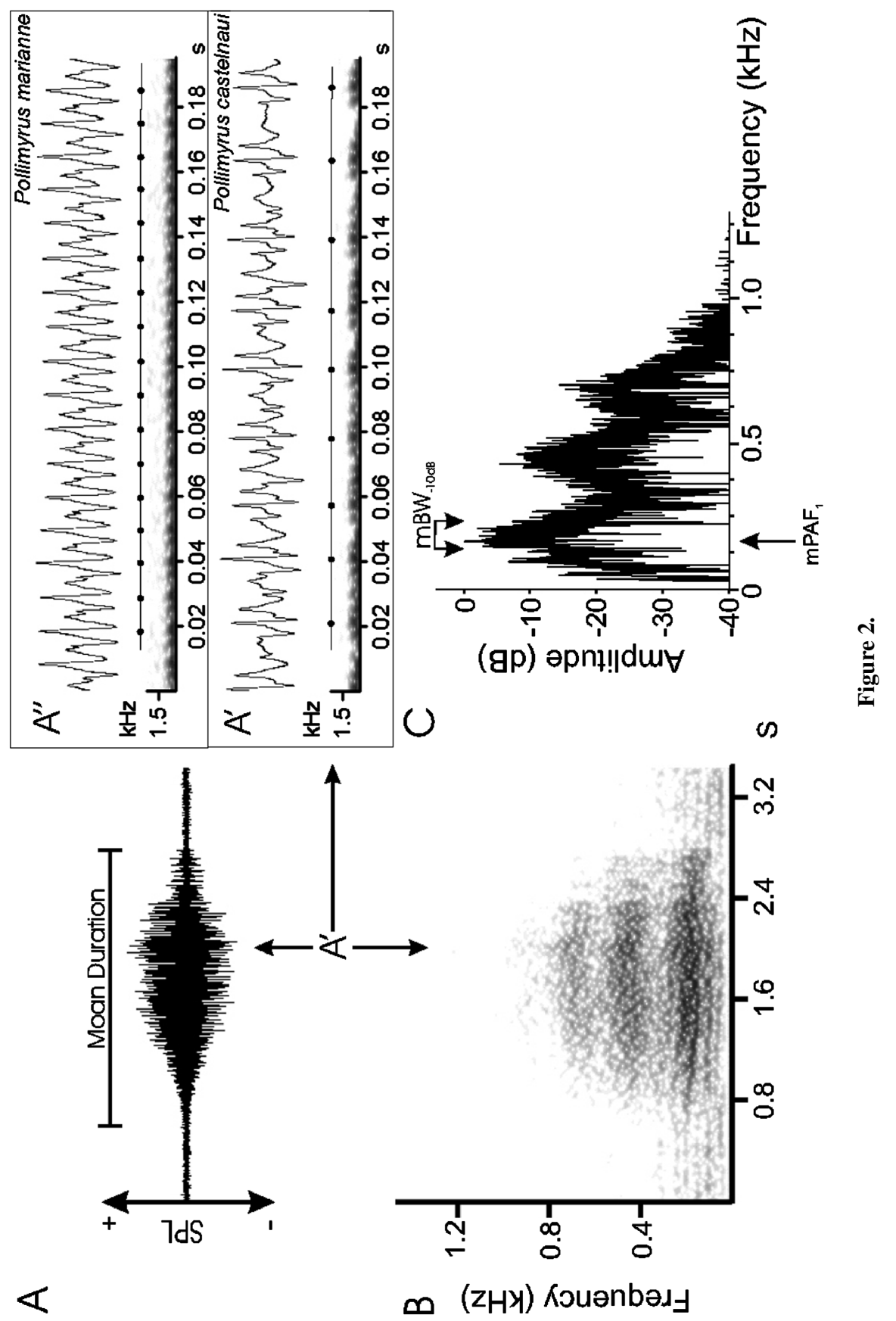


A male ready to reproduce used to moan while patrolling his territory and nest site. When, however, a female was visiting the territory or the nest site, the male generated long-lasting moans superimposed by grunts (MoanGrunt bout, Figure 3A, B). A male did not vocalise when directly engaged in a spawning posture with a female (in which the male was tilted sideways and underneath the female, with anal fins mutually tightly linked). Immediately after separation of the pair, the female used to leave the territory and the male resumed vocalising moans. The courtship behaviour of $P$. castelnaui was very similar to that reported for P. marianne (Lamml \& Kramer, 2005).

Some moan characteristics indicate differences between the two species (Figure 1). Pollimyrus castelnaui moans are composed of three, sometimes four 'noisy' or broad-band components (formants) the peaks of which were only poorly harmonically related amongst each other, in contrast to the more

Figure 2. Acoustic properties of a P. castelnaui moan. (A) Oscillogram, (B) sonogram and (C) amplitude spectrum. $\left(\mathrm{A}^{\prime}, \mathrm{A}^{\prime \prime}\right) \mathrm{A}$ moan is composed of a sequence of many pulse groups: $\mathrm{A}^{\prime}$ for $P$. castelnaui, $\mathrm{A}^{\prime \prime}$ for $P$. marianne, shown at high temporal resolution. The main pulse within each pulse group is indicated by a dot, determined by (1) where strongest amplitudes in the oscillogram were found, and (2) by location of blackest portions of concurrent sonogram, lower panels (temporal resolution, $0.33 \mathrm{~ms}$ ). (B) The sonogram reveals three or four broad bands of high intensity, with most energy at about $160 \mathrm{~Hz}$ (first formant) that corresponds to the fourth harmonic of a fundamental frequency close to $40 \mathrm{~Hz}$, determined by a mean mPGP of $24 \mathrm{~ms}$. Amplitude spectra reveal a broadband mPAFl at $161 \mathrm{~Hz}$ and two weaker peaks of higher frequencies (corresponding to the central frequencies of the second and third formants). The sonogram is based on 1024 point FFTs with a frame size of 50\%, 93.75\% frame overlap and Hamming Window applied. Frequency resolution, $5 \mathrm{~Hz}$; temporal resolution, $10.7 \mathrm{~ms}$; passband filter $40 \mathrm{~Hz}-10 \mathrm{kHz}$.

Figure 3. Moan-Grunt bout of P. castelnaui. (A) Oscillogram, (B) sonogram. (C-C') Oscillograms of a grunt at increasingly higher resolution. A sequence of 43 grunt pulses with a mean gIPI of $34 \mathrm{~ms}$ is composed of acoustic pulses with a mean duration of $3.5 \mathrm{~ms}$. $\left(\mathrm{C}^{\prime}\right)$ Between single grunt pulses, sinusoidal oscillations of lower amplitude representing the superimposed moan are visible. (E) The grunt Peak-Amplitude Frequency (of $1051 \mathrm{~Hz}$ ) was not present in the moan. The oscillations of the superimposed moan show a frequency increase of gPAFl to about $200 \mathrm{~Hz}$ that recedes to about $180 \mathrm{~Hz}$ after termination of the grunt. (F, G) IPI diagrams for 10 grunts of a $P$. castelnaui and $P$. marianne male superimposed (last interval not shown when longer than $60 \mathrm{~ms}$ ). Abscissa, interval number in the order of occurrence; ordinate, IPI duration. (B) The sonogram is based on 1024-point FFTs, with a frame size of $50 \%, 75 \%$ frame overlap (frequency resolution, $11 \mathrm{~Hz}$; temporal resolution, $21.3 \mathrm{~ms}$ ), or (D) $93.75 \%$ frame overlap (frequency resolution, $11 \mathrm{~Hz}$; temporal resolution, $5.33 \mathrm{~ms}$ ) with a Hamming Window applied; passband filter, $40 \mathrm{~Hz}-10 \mathrm{kHz}$. 

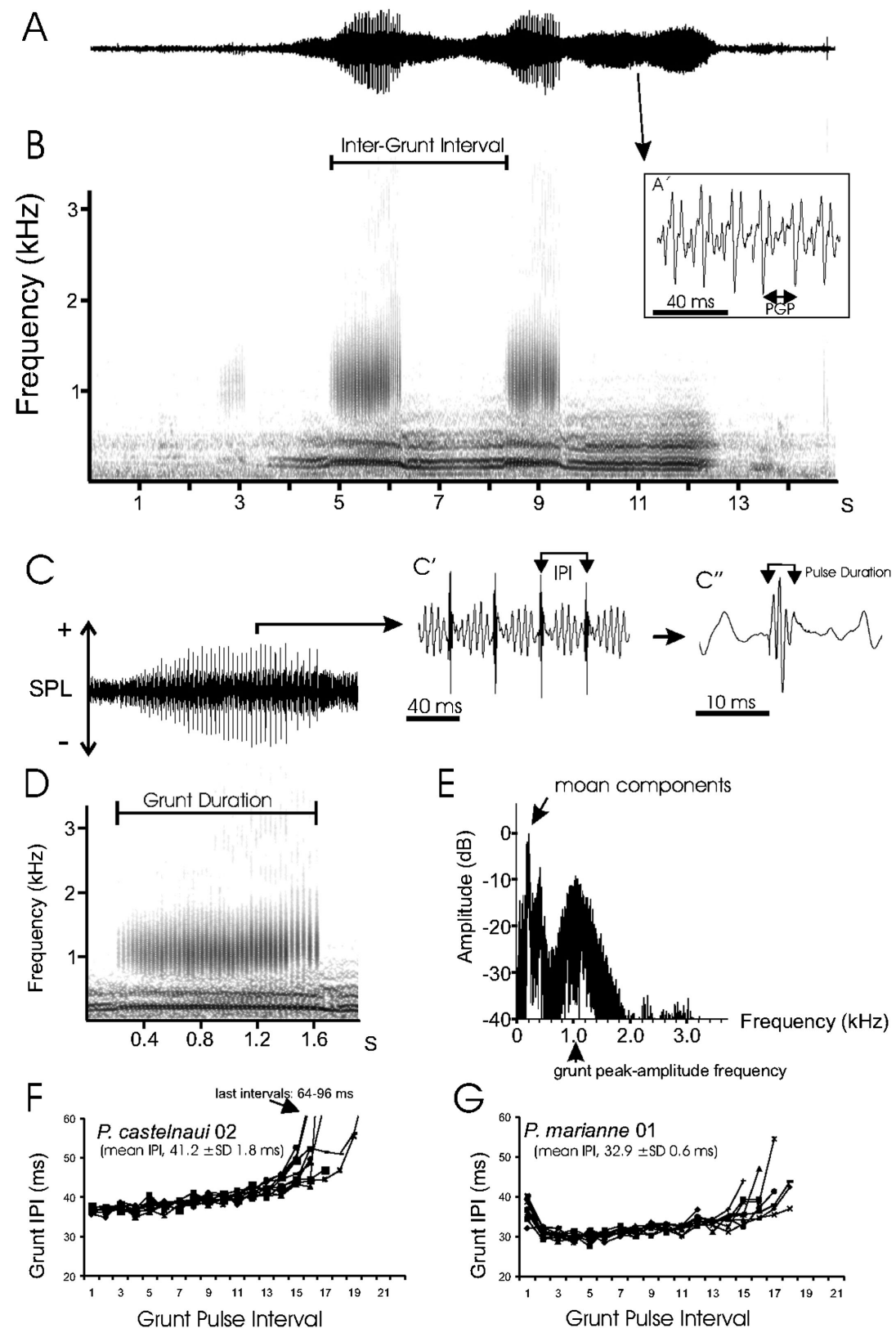

Figure 3. 


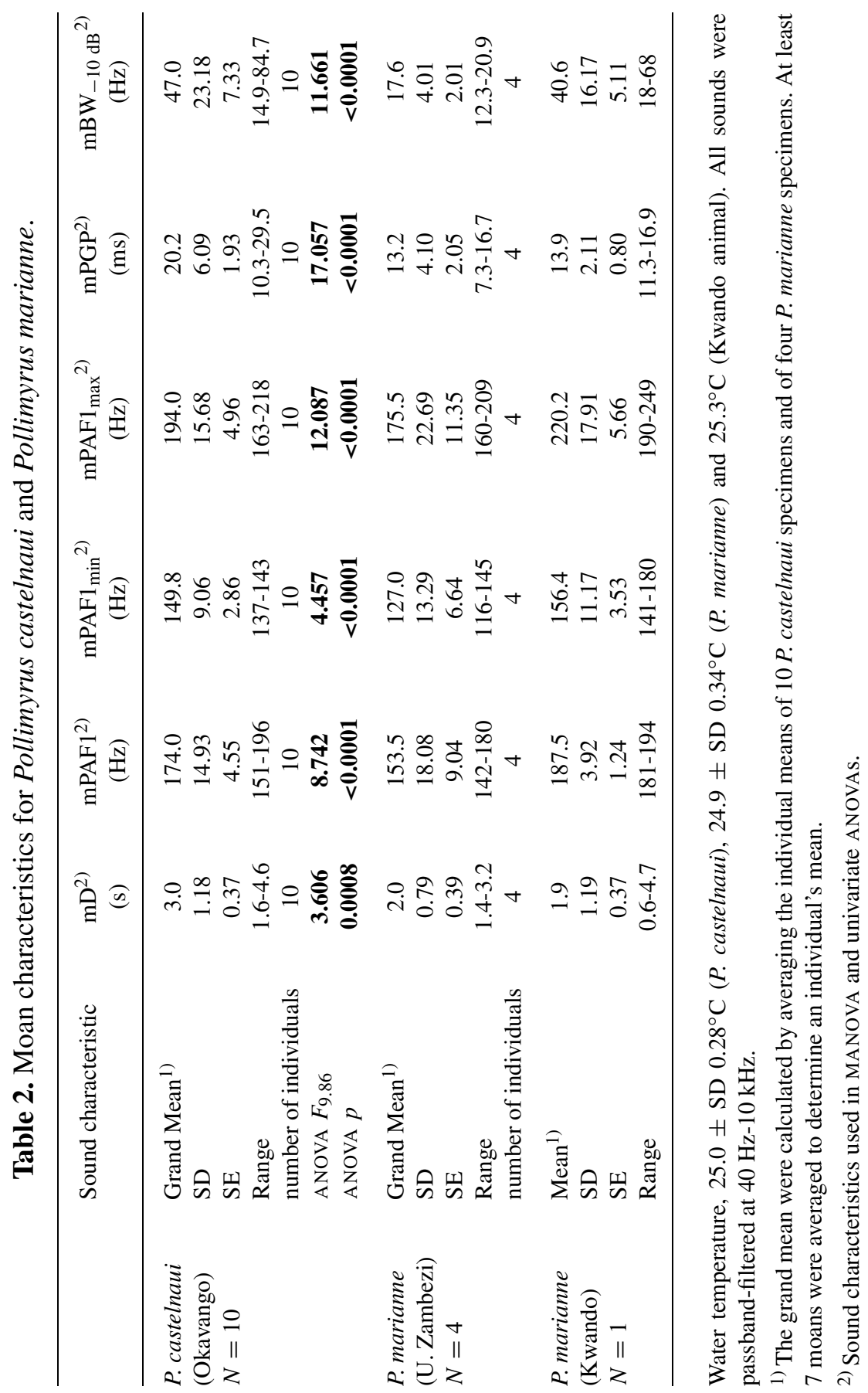


tonal $P$. marianne moans that are characterised by a distinctly narrowband strongest component, which corresponds best to the centre frequency of the first formant in P. castelnaui, and that is here termed Peak-Amplitude Frequency of the first formant, mPAFl (details, Table 2). Even in P. castelnaui, additional spectral lines within the broad-band formants were detectable. The $\mathrm{mBW}_{-10 \mathrm{~dB}}$ around the usually dominant spectral component, mPAF1, was much wider in $P$. castelnaui $(15-85 \mathrm{~Hz}$, Figure 2) than in P. marianne (12$21 \mathrm{~Hz}$, Table 2). In P. castelnaui, in addition to an mPAFl of about $160 \mathrm{~Hz}$, high energy occurred at about $430 \mathrm{~Hz}$ in the second, and at about $700 \mathrm{~Hz}$ in the third formant (Figure 2B, C) which, together with additional spectral components within the first formant, suggest a fundamental frequency of about $40 \mathrm{~Hz}$. In some $P$. castelnaui moans the second formant at about $400 \mathrm{~Hz}$ was stronger than the first (see P. castelnaui 11 in Figure 1A).

The relatively weak harmonic structure of a moan was determined by the fine structure within a pulse group, $\mathrm{mPGP}$, and the precision at which it was repeated. At high temporal resolution, the oscillogram of $P$. castelnaui moans showed identifiable pulse groups repeated hundreds of time. A pulse group consisted of one strong pulse that was followed by a few smaller oscillations. The mPGP varied moderately within the centre part of a moan. Compared to $P$. marianne, $P$. castelnaui individuals generated moans with very long mPGPs (mean mPGP up to $30 \mathrm{~ms}$ ) in the centre part of a moan (Figures $2 \mathrm{~A}^{\prime}, \mathrm{A}^{\prime \prime}$ ), with even longer mPGPs in the terminal section of some moans. For better comparison, we analysed mPGPs of the centre parts, only, where the moans showed the lowest frequency modulation. Seven of ten $P$. castelnaui generated longer mPGPs (P. castelnaui: range, $10-30 \mathrm{~ms}$; mean, $20.2 \mathrm{~ms}$ ) than the $P$. marianne male with the longest mean mPGP of $16.7 \mathrm{~ms}$ (P. marianne: range, 7-16.7 ms; mean, $13.2 \mathrm{~ms}$ ).

Moreover, P. castelnaui moans were often louder than $P$. marianne moans at similar SL and distance from the hydrophone. The absolute SPL for the 'best' moans (and average grunts) of $P$. castelnaui was $110 \mathrm{~dB}$ re: $1 \mu \mathrm{Pa}$ at about $10 \mathrm{~cm}$ from the hydrophone, in contrast to $P$. marianne moans with an SPL of about $104 \mathrm{~dB}$ re: $1 \mu \mathrm{Pa}$ at about the same distance. P. marianne seemed to concentrate their energy of softer moans in a narrow-band spectral component (caused by more constant mPGPs), whereas P. castelnaui vocalised louder and more broad-band moans (caused by more variable mPGPs). 
The moans of one specimen of $P$. marianne from the Kwando River, a presumed hybridisation zone (Kramer et al., 2003), were similar in their mean mPGP of $13.9 \mathrm{~ms}$ to that of P. marianne from the Upper Zambezi (mean mPGP, $13.2 \mathrm{~ms}$ ), but not to $P$. castelnaui's (mean mPGP, $20.2 \mathrm{~ms}$ ). However, the Kwando male's mBW $-10 \mathrm{~dB}$ was $40 \mathrm{~Hz}$ compared to $17 \mathrm{~Hz}$ in P. marianne and $47 \mathrm{~Hz}$ in P. castelnaui (Table 2); thus in this sound characteristic, the Kwando male resembled $P$. castelnaui.

The males of both species also gave moans and rarely grunts during or shortly after what appeared to be purely agonistic interactions directed against both males and females. In $P$. castelnaui, 'agonistic moans' were often very brief, and of a higher frequency than courtship moans (e.g., $\mathrm{mPAF}_{1 \max }, 200 \pm \mathrm{SD} 16 \mathrm{~Hz}$ rather than $188 \pm \mathrm{SD} 8 \mathrm{~Hz}, \geqslant 7$ agonistic moans recorded from Pc 09, Student's $t$-test, $p=0.0667$ ). Pollimyrus castelnaui's agonistic moans resembled those of $P$. marianne in their shorter $\mathrm{mD}$ and higher mPAF1 when compared to courtship moans (Lamml \& Kramer, 2005). For the present species comparison of courtship sounds, we used only vocalisations that were not directly accompanied by overt aggression, such as circling while giving bites or butts.

Pollimyrus castelnaui Moan-Grunt bouts comprised one or many grunts with a highly variable Inter-Grunt Interval (IGI) of 2.8 to $8.8 \mathrm{~s}$ (Figure 3 A, B, Table 3). The duration of a Moan-Grunt bout varied considerably depending on the presence of a gravid female in the male's territory. When a female was present, Moan-Grunt bouts could last up to $58 \mathrm{~s}$, during which the vocalising male did not attack the visiting female. However, the male often terminated a female's visit with a well-aimed bash against the female (in total darkness). The mean duration of Moan-Grunt bouts did not differ between the two species. The IGI was higher in P. castelnaui because of one male's exceptionally long mean IGI of $8.8 \mathrm{~s}$.

A grunt is composed of a short sequence of strong acoustic pulses. The $P$. castelnaui as a group generated grunts that were composed of more pulses than in P. marianne (ranges of the individuals' means: P. castelnaui, 15-34 pulses; $P$. marianne, 13-18 pulses). Accordingly, the mean $\mathrm{gD}$ of $P$. castelnaui $(674 \mathrm{~ms})$ was longer than in $P$. marianne $(546 \mathrm{~ms})$, but the $P$. marianne values were still within the range of $P$. castelnaui.

The $P$. castelnaui grunt in Figure 3C consists of 43 pulses. Grunt pulses always began with a short negative inflection that was followed by a few major oscillations (Figure $3 \mathrm{C}^{\prime \prime}$ ). The mean gPD in P. marianne was longer 


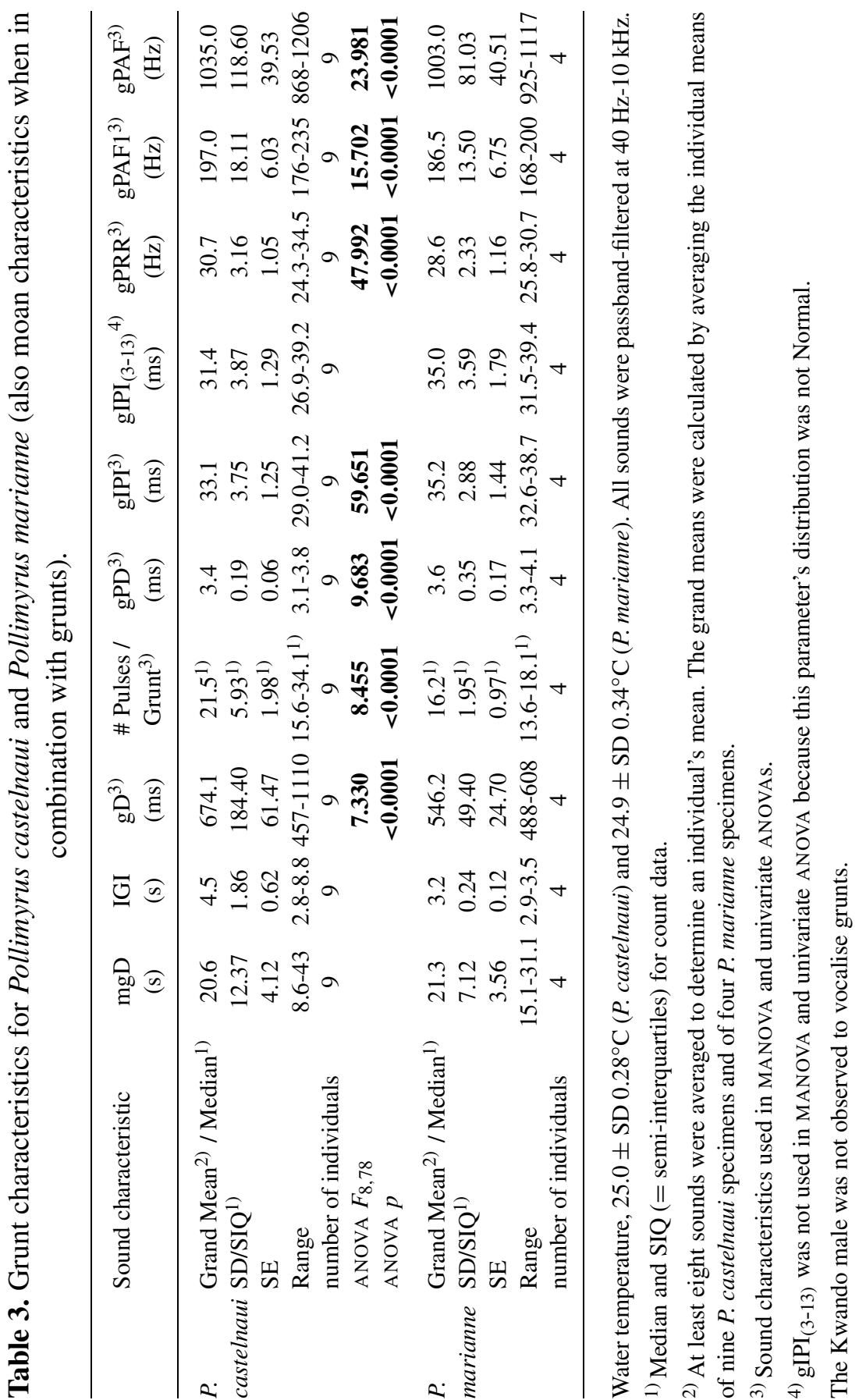


Table 4. Long-term stability of moan and grunt characteristics in P. marianne male 01

\begin{tabular}{|c|c|c|c|c|c|c|}
\hline & & \multicolumn{2}{|c|}{ Moan } & \multicolumn{3}{|c|}{ Grunt } \\
\hline & & Duration (s) & PAF1 (Hz) & Duration (ms) & PAF $(\mathrm{Hz})$ & PRR(Hz) \\
\hline \multirow[t]{3}{*}{ June 2002} & M & 2.58 & 154 & 573 & 922 & 31.5 \\
\hline & SD & 1.39 & 13.3 & 195.7 & 103.4 & 2.3 \\
\hline & $N$ & 106 & 104 & 57 & 57 & 57 \\
\hline \multirow[t]{3}{*}{ June 2004} & $\mathrm{M}$ & 2.81 & 166 & 563 & 888 & 32.5 \\
\hline & SD & 1.03 & 9.3 & 144 & 85 & 1.69 \\
\hline & $N$ & 23 & 23 & 46 & 45 & 46 \\
\hline \multirow[t]{3}{*}{ July 2005} & M & 1.90 & 148 & 539 & 925 & 30.3 \\
\hline & SD & 0.83 & 15.7 & 67.6 & 31.5 & 0.57 \\
\hline & $N$ & 10 & 10 & 10 & 10 & 10 \\
\hline
\end{tabular}

$N$, number of vocalisations.

than in P. castelnaui because of one P. marianne whose mean of $4.1 \mathrm{~ms}$ exceeded that of all other fish. Between grunt pulses, sinusoidal oscillations of the superimposed moan were visible in both species. In moans with long mPGPs, mPGP receded to longer terminal values after a grunt had finished, similar to those that had been generated preceding the grunts (Figure $3 \mathrm{~A}^{\prime}$ ). The grunt amplitude spectrum peaked at $1051 \mathrm{~Hz}$ in this particular example (gPAF). Lower-frequency spectral peaks were caused by the superimposed moan, such as the one at $215 \mathrm{~Hz}$ (Figure 3E). P. marianne males vocalised grunts with similar PAF of $925-1117 \mathrm{~Hz}$ that were within the range of $P$. castelnaui individuals $(868-1206 \mathrm{~Hz})$. Grunt pulses were separated by mean gIPIs of similar duration for both species (33 and $35 \mathrm{~ms}$, Table 3). A few initial gIPIs of long duration were followed by a sequence of gIPIs that were nearly constant or only slowly increasing $\left(\mathrm{gIPI}_{3-13}\right)$, with the very last gIPI of much longer duration (see Figure $3 \mathrm{~F}, \mathrm{G}$ ). The mean gIPI $_{3-13}$ varied considerably between males, but only little within males. Table 4 illustrates the long-term variability of some sound characteristics of $P$. marianne male 01 over three years (June 2002-July 2005). This male's mean gPRR varied between $30.3 \mathrm{~Hz}$ in 2005 and $32.5 \mathrm{~Hz}$ in 2004 at similar temperature. Regarding the sound characteristics of the grunt we were unable to recognize clear species differentiation between $P$. castelnaui and P. marianne.

In many animals, sound characteristics depend on body size. As a rough indicator for body size we used $\mathrm{SL} \times \mathrm{BD}$. Our $P$. castelnaui ranged from 5.4 
to $6.3 \mathrm{~cm}$ in $\mathrm{SL}$, and from 1.45 to $1.91 \mathrm{~cm}$ in BD. None of the P. castelnaui sound characteristics depended on body size, as revealed by leastsquares regression analysis $\left(F_{1,8} \leqslant 2.791, p \geqslant 0.1333\right.$ for $\mathrm{mD}$, mPAFl, $\mathrm{mPAF} 1_{\text {min }}, \mathrm{mPAF}_{1_{\max }}, \mathrm{mPGP}, \mathrm{mBW}_{-10 \mathrm{~dB}}$, IGI, gD, number of grunt pulses, gPD, gPAF, gPRR, gIPI, gIPI ${ }_{3-13}$; one mean value per individual entered in the analysis). The number of $P$. marianne individuals that were available to this study was too small for regression analysis.

\section{Intraspecific variability of sound characteristics in P. castelnaui and P. marianne}

We examined the variability of moan and grunt characteristics between $P$. castelnaui males vs the within-male variability.The hypothesis of no between-male differences among any one of 6 moan characteristics (Table 2) was rejected by MANOVA $\left(F_{\geqslant 9,86} \geqslant 4.808, p<0.0001\right.$; test variables, Wilks' Lambda, Roy's Greatest Root, Hotelling-Lawley Trace, and Pillai Trace). A similar MANOVA result was obtained for the seven grunt characteristics marked on Table $3\left(F_{\geqslant 8,78} \geqslant 9.453, p<0.0001\right)$. Subsequent univaritate ANOVAs showed significant between-male differences for all six moan characteristics (Table 2), and all seven grunt characteristics (Table 3) that were included in the MANOVAs. Therefore, sound characteristics may function as individual markers, perhaps of male quality, in intra- or intersexual selection.

Figure 4 illustrates the considerable between-male variability, using mPGP, gPAF and gIPI as examples for both $P$. castelnaui and $P$. marianne. Table 5 contrasts the two species' within- $\left(\mathrm{CV}_{\mathrm{w}}\right)$ and betweenmale $\left(\mathrm{CV}_{\mathrm{b}}\right)$ variabilities of sound characteristics. In P. castelnaui, the mean within-male variability of $\mathrm{mD}, \mathrm{gD}, \mathrm{IGI}$, and grunt pulse number was very high (29.4-52.7\%), and these sound characteristics therefore appear unsuitable as individual markers $\left(\mathrm{CV}_{\mathrm{b}} / \mathrm{CV}_{\mathrm{w}} \leqslant 0.93\right)$. However, in $P$. castelnaui $\mathrm{mPAF} 1_{\max }, \mathrm{mPGP}$ and $\mathrm{mBW}_{-10 \mathrm{~dB}}$ might serve as individual-specific traits $\left(\mathrm{CV}_{\mathrm{b}} / \mathrm{CV}_{\mathrm{w}} \geqslant 1.13\right)$; a similar conclusion is suggested for the characteristics gPRR, gIPI, gIPI $I_{3-13}$, and gPAF $\left(\mathrm{CV}_{\mathrm{b}} / \mathrm{CV}_{\mathrm{w}} \geqslant 1.7\right)$.

Four $P$. marianne males showed higher between- than within-male variability in the characteristics $\mathrm{mPAF} 1, \mathrm{mPAF} 1_{\max }$, and $\mathrm{mPGP}$, and also in gPAF, gPD, gPRR, gIPI and gIPI ${ }_{3-13}$. All are potentially suitable as individual markers (Table 5). However, in $\mathrm{mBW}_{-10 \mathrm{~dB}}, \mathrm{gD}$, IGI and number of pulses to a grunt $P$. marianne males showed ratios of $\mathrm{CV}_{\mathrm{b}} / \mathrm{CV}_{\mathrm{w}}<1.0$. 

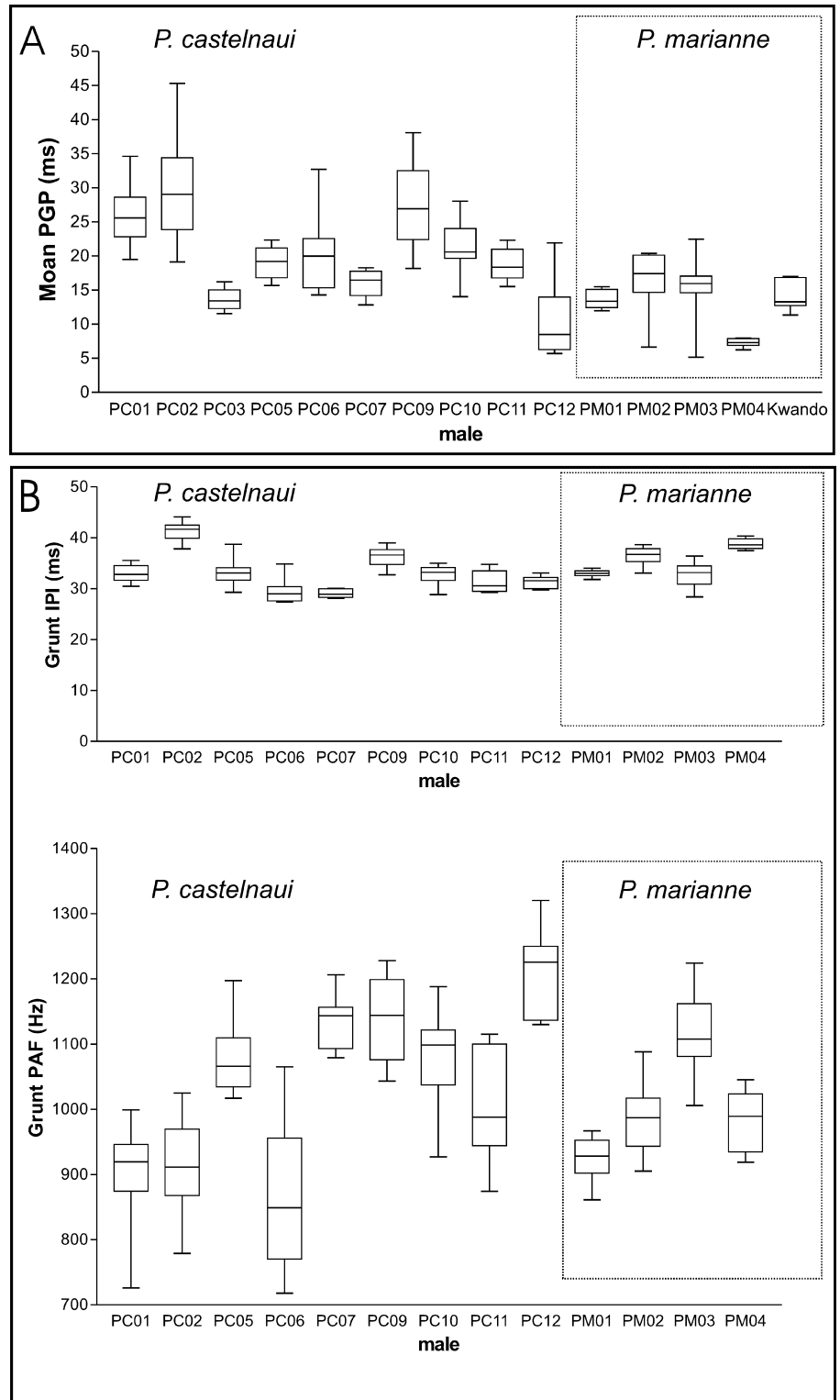

Figure 4. Between-male variability for (A) mPGP, (B) gIPI and gPAF. For gIPI and gPAF, all $P$. marianne males were within the broad range of variation of $P$. castelnaui males. For mPGP, seven of ten P. castelnaui males produced longer mean mPGPs than the P. marianne male with the longest mPGP of $16 \mathrm{~ms}$. The horizontal bar within a box indicates the median. The whiskers give the minimum and maximum value for each individual. The lower and upper box boundaries indicate the 25 th and 75 th percentiles. 


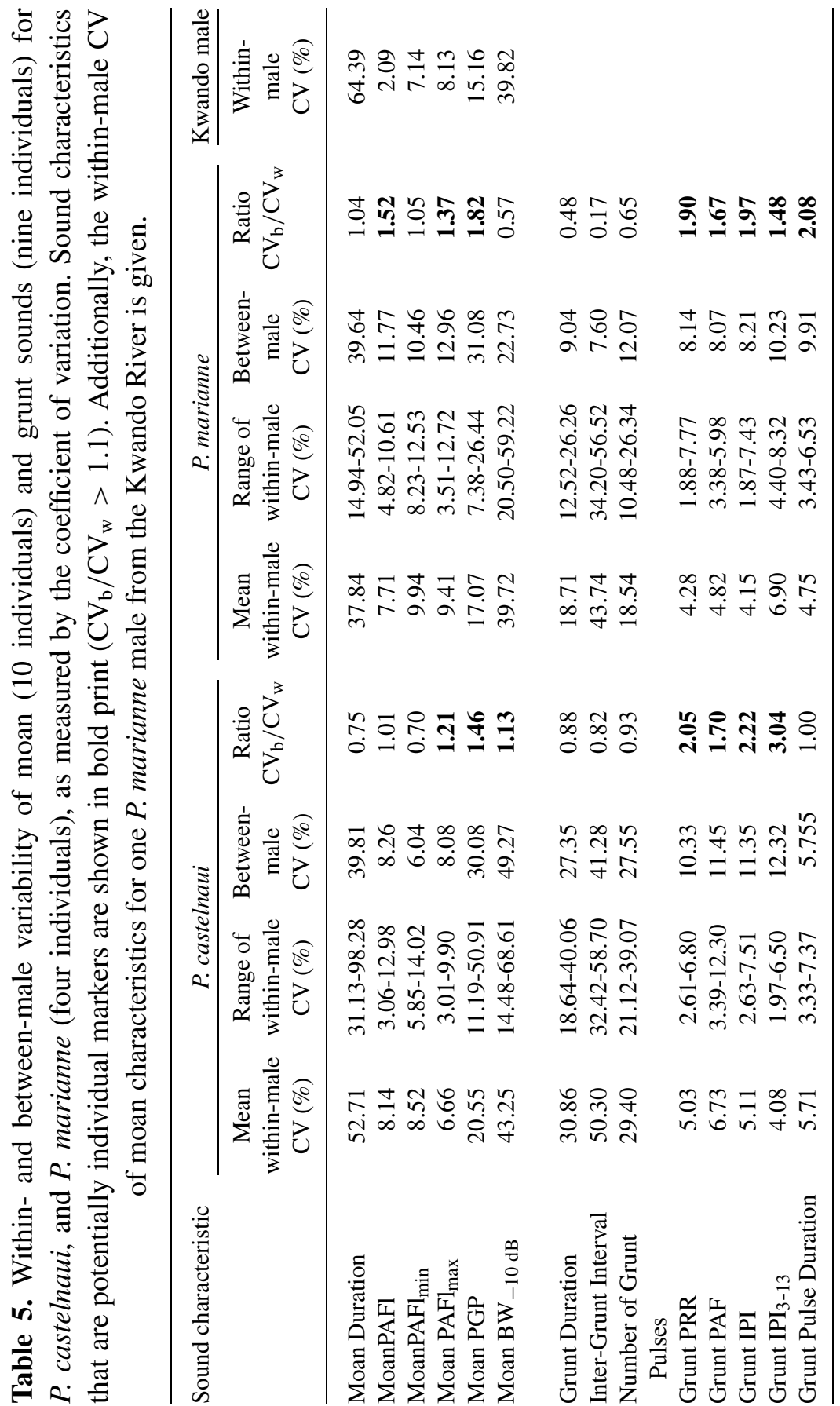


The single $P$. marianne male from the Kwando River resembled $P$. castelnaui in its high within-male variability of $\mathrm{mD}(64.4 \%)$ and low withinmale variability of $\mathrm{mPAF}_{\min }(7.1 \%$; Table 5$)$. In mPAFl (2.1\%) and mPGP $(15.2 \%)$ this male's within-male variability was lower than those of both $P$. castelnaui and P. marianne from the Upper Zambezi River. The Kwando male resembled $P$. marianne from the Upper Zambezi River in its higher within-male variability of $\mathrm{mPAF} 1_{\max }(8.1 \%)$ and in its lower within-male variability of $\mathrm{mBW}_{-10 \mathrm{~dB}}(39.8 \%)$ compared to $P$. castelnaui.

\section{Discussion}

Courtship songs within the genus Pollimyrus

Like males of the sibling species P. marianne (Lamml \& Kramer, 2005), territorial $P$. castelnaui males built nests at the beginning of a reproductive cycle and courted females with two different sound types which they combined into courtship songs: relatively long-lasting moans and short, pulsatile grunts. The vocalisations of both southern African species differed from those of the two West African species, P. adspersus and P. isidori (Crawford et al., 1997b), in the typical sequence of sound patterns, in quantitative parameters of certain sound characteristics, and by the lack of growls and hoots. Pollimyrus castelnaui and P. marianne generated moans and grunts of much longer duration, and grunts of lower gPRR, than the two West African species (Figure 5). In $P$. adspersus, grunts and moans are generated by sonic muscles drumming against the swimbladder (as demonstrated by Crawford \& Huang, 1999), and the same mechanism is assumed for the two southern African species. Differences between southern African and West African species in body size and shape are likely to affect the size of the resonant structure (presumably the swimbladder). However, morphology does not explain differences in display duration, such as in $\mathrm{mD}$ and $\mathrm{gD}$. It is unexplained why the southern African species, called the dwarf stonebashers because they are so small, show lower mPAF1 and gPRR values than the two West African species. This seems to indicate that mPAFl is not only determined by the morphology (size) of the swimbladder but also by the sonic muscle twitch rate.

Nest construction, parental care and complex courtship songs may be shared derived behavioural traits for the genus Pollimyrus. Members of other 

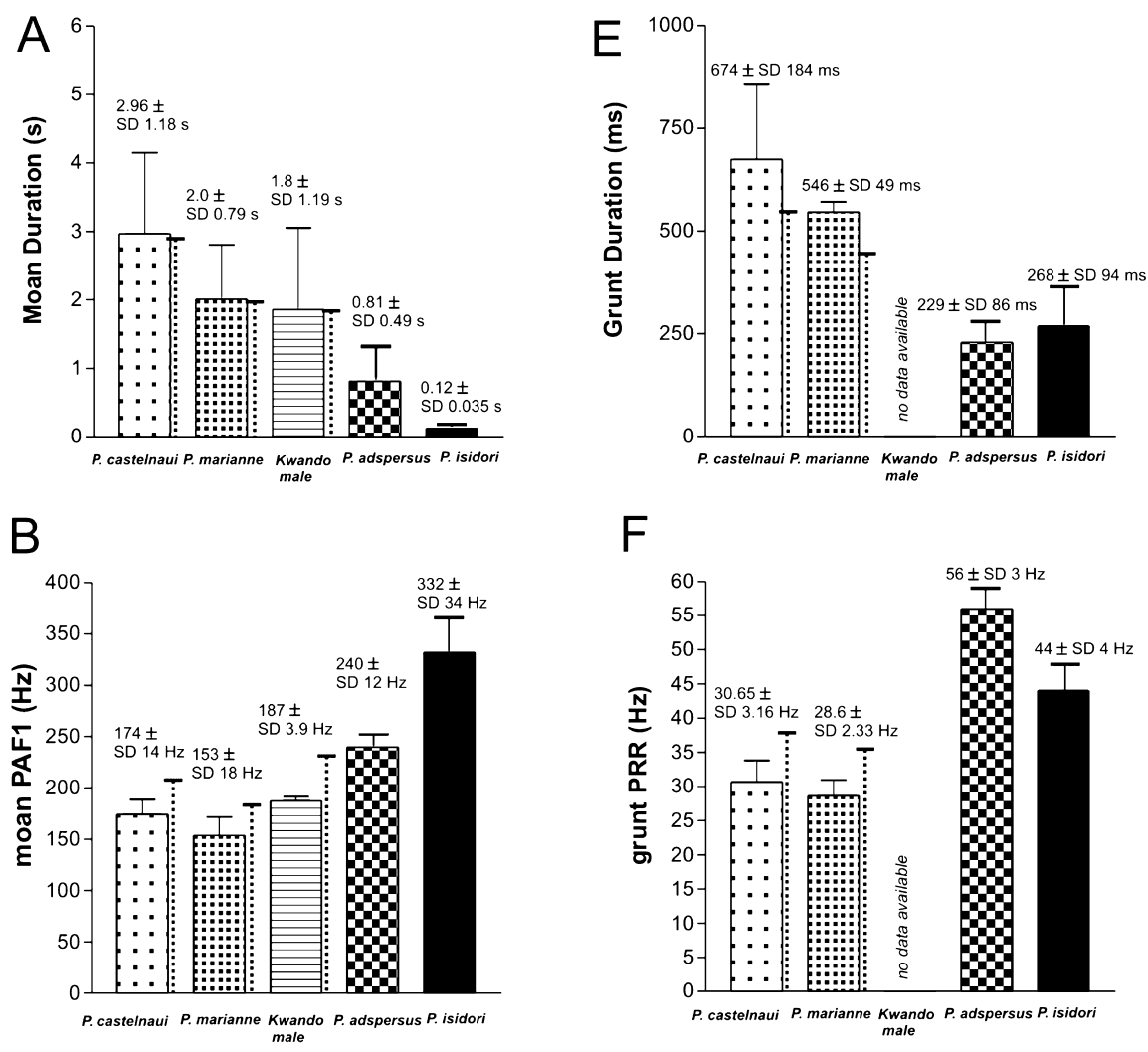

F

C

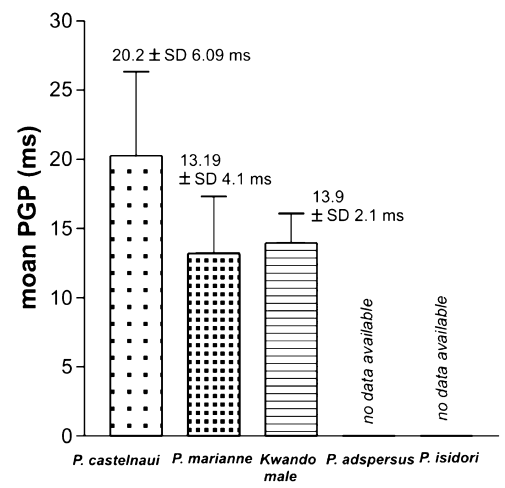

D

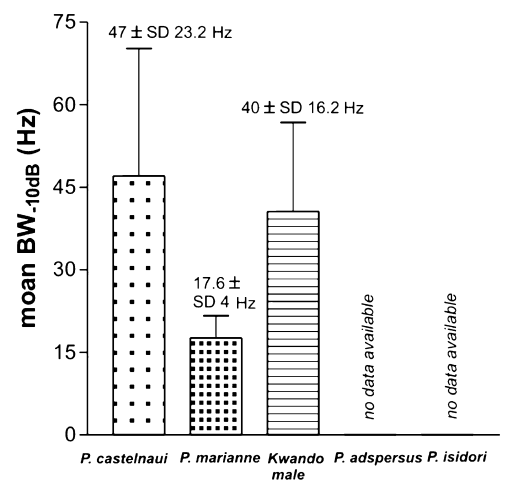

Figure 5. 
mormyrid genera which have reproduced in captivity, such as Marcusenius macrolepidotus from South Africa (Werneyer \& Kramer, 2005), and Mormyrus rume proboscirostris and Campylomormyrus cassaicus (Schugardt, 1997), are unknown to build nests. Whether or not Mormyrus and Campylomormyrus species vocalise is unstudied at present. Growl sounds are also generated by male $M$. macrolepidotus angolensis from the Upper Zambezi during courtship (Lamml \& Kramer, subm.), which are rather simple calls compared to the complex courtship songs within the genus Pollimyrus.

\section{Acoustic differentiation between P. castelnaui and P. marianne}

Few are the data in support of species-specific vocalisations among closely related fish species (Myrberg et al., 1978; Lugli et al., 1995; Crawford et al., 1997b; Lobel, 1998; Amorim et al., 2004). The parapatric sibling species P. marianne and P. castelnaui are differentiated morphologically, genetically, and in their EOD waveforms (Kramer et al., 2003). The Upper Zambezi is sporadically connected with the Okavango via the Linyanti-Chobe system during high floods (at least seven brief periods since 1942). Kwando P. marianne are distinct from Upper Zambezi P. marianne in morphology and EOD waveform, following a geographical cline (increasing differentiation with distance). This is evidence in support of migration and possibly hybridisation between the Kwando and Upper Zambezi Rivers (Kramer et al., 2003).

Although courtship behaviour, the sound elements (moan and grunt), and their combination into songs was similar for both sibling species of the present study, a practised human listener distinguishes between the 'husky' moans of $P$. castelnaui, and $P$. marianne's more tonal moans. Because mPGP in $P$. castelnaui was more variable than in $P$. marianne, $P$. castelnaui moans

Figure 5. Comparison of acoustic characteristics for all members of the genus Pollimyrus known to vocalise courtship songs (data for $P$. adspersus and $P$. isidori taken from Crawford et al., 1997b). A-D, moans; E, F, grunts. Shown are means +1 SD. The vocalisations of $P$. castelnaui and $P$. marianne were recorded at a mean water temperature of $25^{\circ} \mathrm{C}$, whereas those of $P$. adspersus and $P$. isidori were recorded at about $28^{\circ} \mathrm{C}$. Note that with temperature compensation to $28^{\circ} \mathrm{C}$ applied, means change to values indicated by vertical broken lines. Notwithstanding, note clearly higher or lower means for the two tropical species compared with the two southern African species. Note the differences between the two southern African species in $\mathrm{mPGP}$ and $\mathrm{mBW}_{-10 \mathrm{~dB}}$, indicating differentiation. The Kwando male fell in with P. castelnaui for $\mathrm{mBW}_{-10 \mathrm{~dB}}$, but with $P$. marianne for $\mathrm{mPGP}$. 
showed a broad-band spectral structure compared to the more narrow-band, harmonic structure of $P$. marianne moans $\left(\mathrm{mBW}_{-10 \mathrm{~dB}}\right.$, Figure 5). Grunts were quite similar for both species, but $P$. castelnaui generated more pulses per grunt than $P$. marianne (15-34 in $P$. castelnaui; $13-18$ in $P$. marianne) which resulted in a longer mean $\mathrm{gD}$ in $P$. castelnaui. However, the $P$. marianne range was within the limits of the broad range of $P$. castelnaui. As far as can be ascertained from the small number of $P$. marianne males available to this study, the differences in moan characteristics between both species indicate acoustic differentiation between $P$. castelnaui and $P$. marianne, congruent with morphological, genetic, and EOD waveform differentiation as documented by Kramer et al. (2003).

\section{Intraspecific variability and sexual selection}

The cues required for 'specific mate recognition', as proposed by H.E.H. Paterson (1985), may, in certain mormyrids, be provided by the EOD waveform (e.g., the spectacular sexual dimorphism in EOD pulse duration found in Marcusenius macrolepidotus angolensis from the Upper Zambezi; Kramer, 1997). Individual EOD waveform discrimination of $\mu$ s-resolution has been demonstrated in P. adspersus (Graff \& Kramer, 1992; Paintner \& Kramer, 2003), and is apparently present also in M. macrolepidotus (South African form; Hanika \& Kramer, 2005). Untrained, unrewarded P. marianne preferred conspecific playback EODs over those of $P$. castelnaui, whereas the reverse experiment was less clear (Markowski et al., submitted). Is speciesor individual recognition in $P$. castelnaui and $P$. marianne not entirely restricted to the electric modality? Given the presumably very high costs associated with vocalisations that may attract predators, many of which have keen hearing, such as catfish (Clarias gariepinus and C. ngamensis were reported to prey on P. castelnaui in the Okavango delta; Merron, 1993), and characids (such as the tigerfish and the African pike), there must be an important benefit associated with courtship songs.

In $P$. adspersus, auditory sensitivity is best between $200-900 \mathrm{~Hz}$, and matches the spectral range of moans and grunts with peak amplitudes at about $400 \mathrm{~Hz}$ (Marvit \& Crawford, 2000a, 2000b; Fletcher \& Crawford, 2001; Large \& Crawford, 2002). Behavioural studies revealed a discrimination limen of $\pm 8.5 \mathrm{~Hz}$ at a base frequency of around $500 \mathrm{~Hz}$ (Marvit \& Crawford, 2000b), and best temporal click resolution with just noticeable 
differences (jnds) of approximately $0.3 \mathrm{~ms}$ in the $10-15 \mathrm{~ms}$ inter-click interval range (Marvit \& Crawford, 2000b). For another mormyrid generating acoustic clicks, Gnathonemus petersii (Rigley \& Marshall, 1973), auditory evoked brainstem responses showed similar jnds of about $0.5 \mathrm{~ms}$ (Wysocki $\&$ Ladich, 2002). Assuming a similarly acute hearing for P. castelnaui, females should discriminate the tonal moans of $P$. marianne males with a mean mPGP of below $16 \mathrm{~ms}$ from the more 'husky' moans of $P$. castelnaui with longer and more variable mPGPs of about $20 \mathrm{~ms}$. Therefore, mate recognition based on specific courtship songs should be possible between $P$. marianne and $P$. castelnaui individuals, during an encounter which is clearly possible in nature.

Additionally, some sound characteristics might have the potential for individual signatures. Grunts were vocalised during courtship almost exclusively. Mean gIPI was surprisingly stable within, but quite variable between males of both species (29.0-41.2 ms in all P. castelnaui males; $32.6-38.7 \mathrm{~ms}$ in all P. marianne males; Figure 4, Table 3). A high between- but low withinmale variability in sound characteristics is the prerequisite for inter- and intrasexual selection, and also individual recognition (Table 5). In P. castelnaui we did not recognize any dependency of sound characteristics on body size $(\mathrm{SL} \times \mathrm{BD})$, indicating that none of the characteristics we studied may be under sexual selection. By contrast, specific information on sex, size, and perhaps condition is available from $P$. castelnaui's (much less so from $P$. marianne's) EOD waveform (Markowski et al., subm.). Compared to P. castelnaui that produces pentaphasic EODs, $P$. marianne generates triphasic EODs encoding less information, in line with its simpler EOD waveform. A female may identify her partner by individual-specific vocalisations at a greater distance than would be possible by its EOD alone, the reach of which is smaller than that of the vocalisations (Crawford et al., 1986, 1997a).

Pollimyrus marianne may have evolved more precisely harmonic moans than $P$. castelnaui that compensate for being softer by contrasting better from a noisy background. The maximum within-male variability for mPGP was $50 \%$ in P. castelnaui males, but only $26 \%$ in P. marianne males (Table 5). In contrast to $P$. castelnaui, size dependency for mPAF1 seems to be present in $P$. marianne, because a small male $(5.5 \mathrm{~cm} \mathrm{SL})$ produced moans of high mPAF1 at about $180 \mathrm{~Hz}$, and the still smaller Kwando male (SL, $5.2 \mathrm{~cm}$ ) even at $187 \mathrm{~Hz}$, whereas in three larger males this value was around 140 Hz. Therefore, in contrast to $P$. castelnaui, $P$. marianne females may assess 
mate size or quality by acoustic characteristics, indicating a difference in the relative importance of the electric and the acoustic modality in both species that, regarding the EOD, became already apparent from EOD playback experiments (Markowski et al., subm.).

Mormyrids produce electric signals day and night from the time they are small juveniles to the end of their adult lives. In contrast, males of the genus Pollimyrus, including the two southern African species studied here, only sing courtship songs when they are ready to reproduce. This suggests that courtship songs can be at least as important as EODs for intra- and intersexual selection in this sonic mormyrid genus. We suggest species-specific courtship songs as an additional field of study providing useful information for the taxonomy, ethology, and behavioural ecology of mormyrid fish.

\section{Acknowledgements}

We would like to thank F.H. van der Bank (Johannesburg University, Auckland Park, South Africa) and Roger Bills (South African Institute of Aquatic Biodiversity, Grahamstown, South Africa) for sampling and exporting P. castelnaui from the field, and F.H. van der Bank for field support to B.K. The observations and experiments comply with the current laws of Germany. This work was supported by the Deutsche Forschungsgemeinschaft (DFG), grants Kr446/11-3 and Kr446/11-4.

\section{References}

Amorim, M.C.P., Knight, M.E., Stratoudakis, Y. \& Turner, G.F. (2004). Differences in sounds made by courting males of three closely related Lake Malawi cichlid species. - J. Fish. Biol. 65: 1358-1371.

Bratton, B.O. \& Kramer, B. (1989). Patterns of the electric organ discharge during courtship and spawning behavior in the mormyrid Pollimyrus isidori. — Behav. Ecol. Sociobiol. 24: 349-368.

Crawford, J.D. (1997). Hearing and acoustic communication in mormyrid electric fishes. Mar. Fresh. Behav. Physiol. 29: 65-86.

Crawford, J.D., Hagedorn, M. \& Hopkins, C.D. (1986). Acoustic communication in an electric fish Pollimyrus isidori (Mormyridae). — J. Comp. Physiol. A. 159: 297-310.

Crawford, J.D., Jacob, P. \& Bénech, V. (1997a). Sound production and reproductive ecology of strongly acoustic fish in Africa: Pollimyrus isidori, Mormyridae. - Behaviour 134: 677-725.

Crawford, J.D., Cook, A.P. \& Heberlein, A.S. (1997b). Bioacoustic behavior of African fishes (Mormyridae): Potential cues for species and individual recognition in Pollimyrus. J. Acoust. Soc. Am. 102: 1200-1212.

Crawford, J.D. \& Huang, X. (1999). Communication signals and sound production mechanisms of mormyrid electric fish. - J. Exp. Biol. 202: 1417-1426. 
Fletcher, L.B. \& Crawford, J.D. (2001). Acoustic detection by sound-producing fishes (Mormyridae): The role of gas-filled tympanic bladders. — J. Exp. Biol. 204: 175-183.

Graff, C. \& Kramer, B. (1992). Trained weakly-electric fishes Pollimyrus isidori and Gnathonemus petersii (Mormyridae, Teleostei) discriminate between waveforms of electric pulse discharges. - Ethology 90: 279-292.

Hanika, S. \& Kramer, B. (2005). Intra-male variability of its communication signal in the weakly electric fish, Marcusenius macrolepidotus (South African form), and possible functions. - Behaviour 142: 145-166.

Kramer, B. (1997). A field study of African elephantfish (Mormyridae, Teleostei): Electric organ discharges in Marcusenius macrolepidotus (Peters, 1852) and Petrocephalus catostoma (Günther, 1866) as related to sex. - J. Afr. Zool. 111: 313-341.

Kramer, B., van der Bank, F.H., Flint, N., Sauer-Gürth, H. \& Wink, M. (2003). Evidence for parapatric speciation in the mormyrid fish, Pollimyrus castelnaui (Boulenger, 1911) from the Okavango - Upper Zambezi River Systems: P. marianne sp. nov., defined by electric organ discharges, morphology and genetics. - Environ. Biol. Fish. 67: 47-70.

Lamml, M. \& Kramer, B. (2005). Sound production in the reproductive behaviour of the weakly electric fish Pollimyrus marianne Kramer et al. 2003 (Mormyridae, Teleostei). - Bioacoustics 15: 1-28.

Large, E.W. \& Crawford, J.D. (2002). Auditory temporal computation: interval selectivity based on post-inhibitory rebound. - J. Comput. Neurosci. 13: 125-142.

Lobel, P.S. (1998). Possible species specific courtship sounds by two sympatric cichlid fishes in Lake Malawi, Africa. — Environ. Biol. Fish. 52: 443-452.

Lugli, M., Pavan, G., Toricelli, P. \& Bobbio, L. (1995). Spawning vocalizations in male freshwater gobiids (Pisces, Gobiidae). — Environ. Biol. Fish. 43: 219-231.

Marvit, P. \& Crawford, J.D. (2000a). Auditory thresholds in a sound-producing electric fish (Pollimyrus): Behavioral measurements of sensitivity to tones and click trains. - J. Acoust. Soc. Am. 107: 2209-2214.

Marvit, P. \& Crawford, J.D. (2000b). Auditory discrimination in a sound-producing electric fish (Pollimyrus): Tone frequency and click-rate difference detection. - J. Acoust. Soc. Am. 108: 1819-1825.

Merron, G.S. (1993). Pack-hunting in two species of catfish Clarias gariepinus and C. ngamensis in the Okavango Delta, Botswana. - J. Fish. Biol. 43: 575-584.

Myrberg, A.A. Jr., Spanier, E. \& Ha, S.J. (1978). Temporal patterning in acoustical communication. - In: Contrasts in behavior (Reese, E. \& Lighter, F., eds). Wiley, New York, p. 138-179.

Paintner, S. \& Kramer, B. (2003). Electrosensory basis for individual recognition in a weakly electric, mormyrid fish, Pollimyrus adspersus (Günther, 1866). — Behav. Ecol. Sociobiol. 55: 197-208.

Paterson, H.E.H. (1985). The recognition concept of species. - In: Transvaal Museum Monography, No. 4. Species and speciation. Transvaal Museum, Illus, Pretoria, South Africa, p. 21-30.

Rigley, L. \& Marshall, J. (1973). Sound production by the elephantnose fish, Gnathonemus petersii (Pisces, Mormyridae). — Copeia 1973: 134-135.

Schugardt, C. (1997). Experimentelle Untersuchungen zur exogenen Kontrolle der zyklischen Fortpflanzung afrikanischer Süßwasserfische: Vergleich von Mormyriden und Polypterus. — Doctoral Dissertation, Humboldt-Universität of Berlin. 
Werneyer, M. \& Kramer, B. (2005). Electric signalling and reproductive behaviour in a mormyrid fish, the bulldog Marcusenius macrolepidotus (South African form). - J. Ethol. 23: 113-125.

Wysocki, L.E. \& Ladich, F. (2002). Can fishes resolve temporal characteristics of sounds? New insights using auditory brainstem responses. - Hearing Research 169: 36-46. 